\title{
Aspects of Residential and Neighbourhood Preferences in the Warri Metropolis, Delta State, Nigeria
}

\author{
Julius O. Gbakeji and Ojeifo O. Magnus \\ Department of Geography and Regional Planning, Ambrose Alli University, \\ P.M.B.14 Ekpoma, Nigeria \\ E-mail: ojbliss07@yahoo.com
}

KEYWORD Housing; locality; choice; Nigeria

\begin{abstract}
This paper examines the residential and neighbourhood preferences of residents in the Warri metropolis in Nigeria. Twenty five neighbourhoods in Warri were selected for this study. Primary and secondary sources of data were used to collect data for this study. Using three indicators of residential desirability the quality of each neighbourhood was ascertained. To determine the level of preference of the each neighbourhood, this research used seven criteria. Our findings reveal that residents generally placed more emphasis on environmental quality, proximity to and availability of, neighbourhood facilities and the quality of the immediate surroundings when taking decisions on where to relocate to within the urban space.
\end{abstract}

\section{INTRODUCTION}

Residential mobility and housing decisions underlie much of urban growth and change $(\mathrm{Wu}$, 2003). Just as housing consumption is of prime importance to an individual's well-being, so also is the process of residential location and relocation central to our understanding of urban dynamics and the changing social and spatial stratification in our cities.

The impossibility of everyone living where they would prefer is not debatable. This presupposes some form of competition for the most desired locations, resulting in a situation where price plays a crucial role in limiting the options available. However, the restricted choice which is an offshoot of this competition for the most desired locations may be considerably reduced as a result of the variation between people in the locations and lifestyles they prefer. For instance, while some people may choose a city-centre location, others may prefer a suburban one, and yet others, an intermediate-urban one. It must be stressed, though, that the reasons for choice of locations among different people are very varied. These include access to employment, business, educational, cultural or recreational opportunities and affordability. Others are familiarity with one location or type of location, perhaps as a result of growing up there; dwelling characteristics such as age, number of rooms, type of appliances or facilities available; or emotional attachment to a place or a lifestyle (Garling and Friman, 2002). One approach therefore, to understanding preferences for different locations is to study the degree of similarity in the choices made by people who are similar to each other and by those who differ. Our principal objective in this paper is to analyse, in detail, the various aspects of residential and neighbourhood preferences in the Warri metropolis from the point of view of residents.

\section{METHODOLOGY}

Data used in this study were obtained from both primary and secondary sources. The primary sources included questionnaire, oral interviews and personal observations. A total of 800 questionnaire were administered across the twenty-five neighbourhoods covered in this study. The neighbourhoods are listed in Table 1. Thirtytwo (32) questionnaires each were administered in each neighbourhood. Within each neighbourhood, all existing streets were given identification numbers and, using systematic random sampling technique, every $3^{\text {rd }}$ street was selected for detailed survey. Furthermore, along each selected street, we used the same sampling technique to select houses for interviews. We used an interval of five (5) for this exercise. Where there were more than one (1) household in a building, the simple random sampling technique was further employed to select one household for interview.

The questionnaire was designed to obtain information from residents about their socioeconomic characteristics such as age, sex, educational level, occupation, and present residences and relocation history. The questionnaire also 
enabled information about residents' residential and neighbourhood preferences with respect to physical environmental features, social environmental features, neighbourhood facilities and housing structural features to be obtained. Residents were asked to provide responses on a preference scale based on a five-point Likert scale in which a score of 5 stands for very good/highly preferred; 4 for good/moderately preferred; 3 for average/just preferred; 2 for fair/fairly preferred; and $1 \mathrm{for} \mathrm{bad} / \mathrm{not}$ preferred while 0 is undecided. Oral interviews were also conducted with a cross section of residents in some neighbourhoods, estate agents and officials of the Delta State Development and Property Authority, Warri. These interviews combined with detailed personal observations, were used to obtain and up-date information on the general residential environment for the study.

Secondary data were obtained from sources such as published books and articles in journals. The data from both sources were analyzed descriptively and statistically.

\section{RESULTS AND DISCUSSION}

Indicators of Residential and Neighbourhood Preferences

In order to enable us carry out an objective analysis of the residential and neighbourhood preferences of residents the Warri metropolis, it is necessary that we identify quantifiable indices by which their preferences can be scientifically measured. To do this, respondents were asked to indicate their residential and neighbourhhood preferences using the following three indices or indicators of residential desirability, namely:

1. the dwelling unit;

2. the physical structure of the neighbourhood of residence, in terms of the nature, mix and intensity of land use; and

3. the neighbours who represent the social dimension of the residential environment.

Each indicator was disaggregated into components, which were then measured on a 5point Likert scale. A score of 5 stands for "very good/highly preferred'; 4 for' good/moderately preferred'; 3 for 'average/just preferred'; 2 for 'fair/fairly preferred'; and 1 for 'bad/not preferred'. The mean score for each component of an indicator is computed by dividing the total respondent score by the number of respondents. The mean scores of each component of an indicator are then summed to give the overall preference score for the indicator. These indicators are now discussed in turn in the subsequent subsections of this paper.

1. Quality of the Dwelling Unit: For the purpose of assessing the contributions of the quality of the dwelling unit of the resident and neighbourhood preferences of residents across all the study neighbourhoods, indices of residential desirability such as toilet and kitchen facilities, space for family interaction, electricity and pipe-borne water, construction materials, ventilation, privacy, and so on, were measured. The results are presented in Table 1

Table 1 shows that the three most preferred neighbourhoods in the Warri metropolis with respect to the quality of the dwelling unit are Ejeba, Bendel Estate, and Okumagba Layout, in that order. They have mean scores of $43.08,42.74$ and 40.25 , respectively, which are well above the city-wide average of 33.44. At bottom of the preference scale are Agbassa, Igbudu-Hausa Quarters and Alderstown with mean scores of 27.13, 27.26 and 27.31; respectively. Thirteen out of the twenty-five study neighbourhoods have below city-wide average scores, indicating the

Table 1: Respondents' assessment of the quality of the dwelling unit by neighbourhood.

\begin{tabular}{lcr}
\hline Neighbourhood & $\begin{array}{c}\text { Overall preference } \\
\text { score }\end{array}$ & Rank \\
\hline Agaga Layout & 38.45 & 4 \\
Agbassa & 27.13 & 25 \\
Ajamogha & 31.90 & 16 \\
Aladja & 33.21 & 13 \\
Alderstown & 27.31 & 23 \\
Bendel Estate & 42.74 & 2 \\
Effurun East & 35.43 & 7 \\
Effurun West & 34.37 & 11 \\
Ejeba & 43.08 & 1 \\
Ekpan & 33.20 & 14 \\
Enerhen Rd-Udu Bridge Area & 35.33 & 9 \\
Enerhen Village-Leventis Area & 36.18 & 6 \\
Essi Layout & 34.50 & 10 \\
Igbudu-Hausa Quarters & 27.26 & 24 \\
OMarket Rd. Area & 29.84 & 19 \\
Midwest College Area & 30.07 & 18 \\
Obahor-Nelson Williams & 32.11 & 15 \\
Odion-Obire Iyara & 28.72 & 21 \\
Ogberikoko & 28.19 & 22 \\
Ogunnu & 37.43 & 5 \\
Okere & 31.06 & 17 \\
Okumagba Layout & 40.25 & 3 \\
Ovwian & 35.41 & 8 \\
P.T.I Rd Area & 33.70 & 12 \\
Pessu & 29.23 & 20 \\
City-wide Average & 33.44 & \\
Source: Find Survera & &
\end{tabular}

Source: Field Survey, 2005 
aging and decaying physical structures of the dwellings in these neighbourhoods. In some of the buildings, particularly in the multi-tenement dwellings, the individual rooms are considerably small, mostly 2.5 by 3 meters on the average. Ventilation in some of such houses is very poor. In addition, tenants share kitchen and toilet facilities in these dwellings. There is considerable overcrowding in some of these houses, overloading and putting pressure on the few housing facilities available.

2. Physical Structure of Neighbourhood of Residence: The desire to have a good or impressive physical environmental quality can be said to behind the practice of urban planning and design, the principal aim of which is to create a better environment in the overall interest of safety, health, aesthetics, comfort and general welfare (Rapoport, 1983; Omuta, 1986; Mokhtarian, 2003; Skifter, 2004). The role that neighbourhood physical and environmental quality plays in residential preference cannot be over-emphasized. To underpin its importance in this regard, the following components of the environmental structure of the neighbourhood, namely: neighbourhood topography, drainage and micro-

Table 2: Respondents' assessment of the physical/ environmental structure of neighbourhood.

\begin{tabular}{|c|c|c|}
\hline Neighbourhood & $\begin{array}{l}\text { verall preference } \\
\text { score }\end{array}$ & Rank \\
\hline Agaga Layout & 36.48 & 6 \\
\hline Agbassa & 27.26 & 24 \\
\hline Ajamogha & 35.51 & 12 \\
\hline Aladja & 34.91 & 16 \\
\hline Alderstown & 32.28 & 21 \\
\hline Bendel Estate & 39.75 & 1 \\
\hline Effurun East & 35.73 & 11 \\
\hline Effurun West & 36.60 & 5 \\
\hline Ejeba & 38.16 & 2 \\
\hline Ekpan & 35.29 & 13 \\
\hline Enerhen Rd-Udu Bridge Area & 36.12 & 8 \\
\hline Enerhen Village-Leventis Area & 36.07 & 9 \\
\hline Essi Layout & 34.08 & 18 \\
\hline Igbudu-Hausa Quarters & 27.83 & 23 \\
\hline Market Rd. Area & 34.12 & 17 \\
\hline Midwest College Area & 34.96 & 15 \\
\hline Obahor-Nelson Williams & 35.00 & 14 \\
\hline Odion-Obire Iyara & 32.74 & 20 \\
\hline Ogberikoko & 35.00 & 14 \\
\hline Ogunnu & 36.84 & 4 \\
\hline Okere & 33.97 & 19 \\
\hline Okumagba Layout & 37.49 & 3 \\
\hline Ovwian & 35.95 & 10 \\
\hline P.T.I Rd Area & 36.15 & 7 \\
\hline Pessu & 32.15 & 22 \\
\hline City-wide Average & 34.82 & \\
\hline
\end{tabular}

Source: Field Survey, 2005. climate, housing density, land use compatibility, neighbourhood flood level, vehicular traffic, open spaces/playgrounds, etc, were measured across all the study neighbourhoods. Their scores across the neighbourhoods are presented in Table 2.

With respect to the physical structure of neighbourhood of residence, Bendel Estate, Ejoba aned Okumagha Layout stand out prominently as the most desirable neigbhour-hoods and are, consequently, the most highly preferred by respondents. The overall preference scores of these neighbourhoods are $39.75,39.16$ and 37.49 , respectively. These figures are to be compared with the city-wide average score of 34.82 . The conclusion that may be drawn from these statistics is that these neighbourhoods are very highly preferred austensibly because of their wellplanned layouts, availability of good and functioning neighbourhood public facilities, high standard of environmental sanitation and the relatively low level of neighbourhood social problems.

On the other hand, the three least preferred neighbourhoods in terms of residential desirability with respect to the physical structure of neighbourhood of residence are Agbassa, IgbuduHausa Quarters and Pessu, respectively, in that other. A common feature of these neighbourhoods is the congested nature of the buildings. The unplanned nature of these neighbourhoods is strongly reflected in the disorderly pattern in which most of the buildings are arranged. The drainage of these neighbourhoods is extremely poor. It is in these neighbourhoods that one commonly finds roads on much higher ground than their surroundings. The side effect of this feature is that during heavy downpours, water is drained from the roads into nearby buildings. Taken generally, the quality of these neighbourhoods is comparatively low.

3. The Social Dimension of the Residential Environment: The social setting of a neighbourhood certainly plays a very significant role in increasing or decreasing its residential desirability by residents. For a residential environment to be desirable, it must symbolize desirable aspects of our wider social world. People, for example, want their neighbourhood and their neighbours to reflect their own status. Perceive similarities with neighbours are consequently very important in residential satisfaction and desirability. As a result, most social groups often wish to live 
with people like themselves, that is, there is an implicit desire for social segregation. The level of crime and/or the image or reputation of residential neighbourhoods is equally important factor influencing the preferences for them. In order to make a clearer understanding of the social dimension of residential neighbourhoods in the Warri metropolis possible, the following components of neighbourhood social setting, namely; nearness to friends and relations, suitability of neighbourhood for raising children, compatibility of neighbours, level of crime and other social vices, among others were analyzed. The results are presented in Table 3.

Table 3 shows that Okumagba Layout ranks first as the most preferred neighbourhood, with respect to neighbourhood social dimension. It has an overall preference score of 37.14. Ejeba and Bendel Estate are second and third with overall preference score of 36.09 and 35.63, respectively. These figures are higher than the city-wide average score of 33.01. The least preferred neighbourhoods is Igbudu-Hausa quarters. On the whole nine out of the twentyfive study neighbourhood have overall preference scores below the city-wide average.

Table 3: Residents' assesment of neighbourhood social dimension by neighbourhood

\begin{tabular}{lcr}
\hline Neighbourhood & $\begin{array}{c}\text { Overall preference } \\
\text { score }\end{array}$ & Rank \\
\hline Agaga Layout & 34.41 & 8 \\
Agbassa & 28.90 & 23 \\
Ajamogha & 29.93 & 22 \\
Aladja & 30.30 & 20 \\
Alderstown & 32.01 & 18 \\
Bendel Estate & 35.63 & 3 \\
Effurun East & 34.00 & 10 \\
Effurun West & 35.61 & 4 \\
Ejeba & 36.09 & 2 \\
Ekpan & 33.14 & 12 \\
Enerhen Rd-Udu Bridge Area & 34.14 & 9 \\
Enerhen Village-Leventis Area & 33.75 & 11 \\
Essi Layout & 32.89 & 16 \\
Igbudu-Hausa Quarters & 27.21 & 24 \\
Market Rd. Area & 33.11 & 13 \\
Midwest College Area & 32.89 & 16 \\
Obahor-Nelson Williams & 33.01 & 15 \\
Odion-Obire Iyara & 32.43 & 17 \\
Ogberikoko & 31.03 & 19 \\
Ogunnu & 34.51 & 7 \\
Okere & 33.07 & 14 \\
Okumagba Layout & 37.14 & 1 \\
Ovwian & 35.00 & 6 \\
P.T.I Rd Area & 35.01 & 5 \\
Pessu & 30.00 & 21 \\
City-wide Average & 33.01 & \\
\hline Source: & &
\end{tabular}

Source: Field Survey, 2005

\section{Preference Levels of Residents Across All Neighbourhoods}

As we asserted in the introductory section of this paper, an invaluable approach we must adopt in our efforts to clearly understand preferences for different locations is to analysis the degree of similarity in the choices made by people who are similar to each other and by those who differ. To enable us carry out this analysis, respondents were asked to rank their preferences for each of the twenty-five study neighbourhoods in terms of their residential desirability. This they were asked to do by assigning the value of 25 to the most preferred one, and so on, in descending order, with the least preferred having a value of 1 . The mean score for each neighbourhood was then computed by dividing the total respondent score by the number of respondents. The results are presented in Table 4.

Table 4 clearly shows that the three most highly preferred residential neighbourhoods in the Warri metropolis are Ejaba, Bendel Estate and Okumagba Layout, in that order, while at the other end of the preference scale are Pessu, Ogberickoko and Agbassa.

The preferences of residents with regard to

Table 4: Neighbourhood preferences of respondents

\begin{tabular}{lrr}
\hline Neighbourhood & $\begin{array}{c}\text { Overall preference } \\
\text { score }\end{array}$ & Rank \\
\hline Agaga Layout & 18.83 & 4 \\
Agbassa & 9.20 & 23 \\
Ajamogha & 9.84 & 21 \\
Aladja & 12.80 & 14 \\
Alderstown & 10.54 & 19 \\
Bendel Estate & 20.85 & 2 \\
Effurun East & 14.49 & 8 \\
Effurun West & 17.49 & 5 \\
Ejeba & 21.10 & 1 \\
Ekpan & 13.55 & 11 \\
Enerhen Rd-Udu Bridge Area & 13.49 & 12 \\
Enerhen Village-Leventis Area & 14.19 & 10 \\
Essi Layout & 14.38 & 9 \\
Igbudu-Hausa Quarters & 9.69 & 22 \\
Market Rd. Area & 11.79 & 16 \\
Midwest College Area & 13.35 & 13 \\
Obahor-Nelson Williams & 11.19 & 18 \\
Odion-Obire Iyara & 11.57 & 17 \\
Ogberikoko & 8.69 & 24 \\
Ogunnu & 12.44 & 15 \\
Okere & 10.11 & 20 \\
Okumagba Layout & 18.92 & 3 \\
Ovwian & 17.34 & 6 \\
P.T.I Rd Area & 14.81 & 25 \\
Pessu & 7.70 & \\
\hline Source: Field Survey, & & 7005.
\end{tabular}

Source: Field Survey, 2005. 
the residential desirability of neighbourhoods are influenced by a number of factors that are as varied as they are many. Numerous researches for instance, have shown that residential and neighbourhood preferences vary not only with household structure and income, but also with lifestyles and personality factors.

\section{Criteria Used by Respondents in Assessing Neighbourhood Preferences}

In order to determine which neighbourhoods are more highly preferred in the Warri metropolis, respondents were asked to assess each of the twenty-five study neighbourhoods with respect to their residential desirability by providing their responses on a 5-piont likert scale. The assess-ment utilized the following seven indicators, namely:

1. Neighbourhood environmental quality.
2. Qualtiy of immediate surroundings.

3. Neighbourhood social setting.

4. Proximity to and availability of, neighbourhood facilities.

5. Housing aesthetics.

6. Housing facilities.

7. Housing structure.

Each of these criteria was disaggregated into component parts, which were then assessed by the respondents. Respondents were also asked to indicate and rank the criteria they used in selecting their preferred neighbourhoods, in their order of importance. The most important criterion influencing the respondents' preference is to be ranked 1, while the least important one is to be ranked 7 . The resultant mean scores of the rankings are presented in Table 5.

Table 5 reveals the overriding importance of criterion 1 (Neighbourhood Environmental

Table 5: Mean scores of criteria used by respondents in selecting most preferred neighbourhoods.

\begin{tabular}{|c|c|c|c|c|c|c|c|}
\hline \multirow[t]{2}{*}{ Neighbourhood } & \multicolumn{7}{|c|}{ Mean scores } \\
\hline & Criterion 1 & Criterion 2 & Criterion 3 & Criterion & 4 Criterion & 5 Criterion & 6 Criterion 7 \\
\hline Agaga Layout & 2.23 & 3.23 & 4.00 & 3.90 & 4.70 & 4.93 & 5.00 \\
\hline Agbassa & 1.86 & 2.41 & 3.28 & 3.07 & 6.07 & 5.79 & 5.72 \\
\hline Ajamogha & 1.71 & 2.74 & 3.68 & 3.39 & 6.16 & 5.71 & 5.61 \\
\hline Aladja & 1.61 & 2.89 & 3.50 & 2.32 & 6.18 & 5.82 & 6.68 \\
\hline Alderstown & 2.20 & 3.27 & 4.43 & 1.53 & 6.87 & 4.10 & 5.73 \\
\hline Bendel Estate & 1.94 & 2.97 & 4.18 & 2.79 & 5.58 & 4.67 & 5.88 \\
\hline Effurun East & 1.76 & 2.86 & 4.00 & 3.10 & 6.21 & 4.45 & 5.59 \\
\hline Effurun West & 1.90 & 2.90 & 4.20 & 1.90 & 6.93 & 4.83 & 5.67 \\
\hline Ejaba & 2.21 & 2.79 & 4.39 & 1.43 & 6.89 & 5.00 & 5.43 \\
\hline Ekpan & 2.16 & 2.97 & 4.58 & 1.74 & 6.97 & 4.45 & 5.26 \\
\hline Enerhen Rd-Udu Bridge & 2.62 & 2.55 & 4.28 & 1.28 & 6.90 & 4.52 & 5.69 \\
\hline Enerhen Village-Leventies Area & 2.59 & 2.44 & 4.44 & 1.31 & 7.00 & 4.53 & 5.69 \\
\hline Essi Layout & 2.67 & 2.77 & 4.23 & 1.17 & 6.93 & 4.63 & 5.67 \\
\hline Igbudu-Hauaa Quarters & 1.84 & 2.45 & 3.35 & 3.10 & 6.03 & 5.77 & 5.65 \\
\hline Market Rd. Area & 1.72 & 2.81 & 2.66 & 2.34 & 6.19 & 5.66 & 5.63 \\
\hline Midwest College Area & 1.62 & 2.90 & 3.52 & 2.28 & 6.21 & 5.83 & 5.66 \\
\hline Obahor-Nelson Williams & 2.19 & 3.25 & 4.50 & 1.50 & 6.87 & 4.09 & 5.72 \\
\hline Odion-Okire-Iyara & 2.57 & 2.50 & 4.40 & 1.30 & 7.00 & 4.57 & 5.67 \\
\hline Ogberikoko & 2.61 & 2.55 & 4.29 & 1.26 & 7.87 & 4.55 & 5.68 \\
\hline Ogunnu & 2.39 & 3.09 & 3.19 & 3.88 & 4.61 & 5.12 & 5.00 \\
\hline Okere & 1.94 & 2.97 & 4.18 & 1.82 & 6.94 & 4.79 & 5.70 \\
\hline Okumagba Layout & 1.83 & 3.07 & 4.13 & 2.63 & 5.80 & 4.63 & 5.90 \\
\hline Ovwian & 1.80 & 2.93 & 3.97 & 3.23 & 6.13 & 4.33 & 5.60 \\
\hline P.T.I Road Area & 2.21 & 2.79 & 4.38 & 1.41 & 6.83 & 5.03 & 5.48 \\
\hline Pessu & 2.19 & 2.94 & 4.59 & 1.72 & 6.97 & 4.44 & 5.28 \\
\hline City-Wide Average & 2.10 & 2.84 & 4.09 & 2.18 & 6.39 & 4.88 & 5.58 \\
\hline
\end{tabular}

Criterion 1 (Neighbourhood environment quality)

Criterion 2 (Quality of immediate surroundings)

Criterion 3 (Neighbourhood social setting)

Criterion 4 (Proximity to, an avaailability of neighbourhood facitities.)

Criterion 5 (Housing aesthetics)

Criterion 6 (Housing facilities)

Criterion 7 (Housing aesthetics)

Source: Field Survey, 2005 
Quality) in influencing the preference levels of respondents. It has a mean score of 2.10. The next most important criteria are proximity to, and availability of, neighbourhood facilities (2.18) and quality of the immediate surroundings (2.84), in that order. The least important criterion that influenced respondent's neighbourhood preference level is housing aesthetics (with a mean score of 6.39).

\section{CONCLUSION AND RECOMMENDATION}

This paper examined the residential and neighbourhood preference of residents in the Warri metropolis. Since it is not possible for everyone to live where they would prefer, it becomes necessary that choices be made in respect of where to stay in the urban space. The reasons underlying the choices of locations among different people are as many as they are varied. Studying the degree or extent of similarity in the choices made by different people is therefore crucial to understanding preferences for different locations. In this study, indicators of residential and neighbouhood preferences, such as quality of the dwelling unit, physical structure of the neighbourhood of residence in terms of land use and the neighbourhood social setting have been seen to play significant role in the choice of neighbourhood of resident. From our analysis, we discovered that the three most highly preferred residential neighbourhoods in the Warri metropolis are Ejaba, Bendel Estate and Okumagba Layout, in that order, while Pessu, Ogberikoko and Agbassa are the least preferrede.

As shown in this study, not all the neighbouhoods are highly preferred. The status of the neighbourhoods that are not highly preferred can be enhanced for good habitation if the following recommendations are taken. First The quality of the environment of Agbasa, Igbudu-hausa quarters, Pessu, Alderstown,and Essi layout which belong to this category of not highly preferred neighbourhoods should be enhanced. This can be done through the reconstruction and rehabilitation of existing facilities such as schools, roads, recreational facilities, water and shopping centres. The state and the local governments must as a matter of necessity collaborate to achieve this because of the huge financial and material implication.

Apart from this measure, landlords and house owners should be enlightened and encouraged to imbibe the maintenance culture of their properties so as to increase their attractiveness and satisfaction to residents. This measure if adopted could appreciably increase the attractive-ness of the houses in addition to enhancing the aesthetic quality of the neighbourhoods in general.

Furthermore, to enhance a less stressful intraurban residential mobility process, the govern-ment should be involved in massive housing construction especially for its workers and low-income groups in the society. It should also create the right atmosphere for individual developers and corporate organizations to participate more actively in solving the housing question. This may be achieved by the enactment of relevant by-laws to make the acquisition of land for housing and property development less cumber-some.

\section{REFERENCES}

Garling T. and M. Friman. 2002. "A Psychological Conceptualization of Residential Choice and Satisification", (pp. 55-80) in J. A. Aragones, G. Francescato and T. Garling (eds.), Residential Environments: Choice, Satisficiation and Behaviour. Westport, CT.: Bergin and Garvey.

Mokhtarian, P.L. 2003. "The Extent and Determinants of Dissonance between actual and preferred Residential Neighbourhood Type". Environment and Planning B, 12: 804-820

Omuta, G.E.D. 1986. "Mininmum versus Affordable Environmental Standards in third World Cities: An Examination of Housing Codes in Benin City, Nigeria." Cities, 3: 58-71.

Rapoport, A. 1983. "Environmental Quality, Metropolitan Areas and Traditional Settlements." Habitat International, 7: 37.

Skifter, A.H. 2004. "Residents Understanding of Deprived Urban Neighbourhoods and its Significance for Plans to move." Paper Presented at the ENHR Conference, in Cambridge, UK. July 2 -6 2004.

Wu, F. 2003."Transitional Cities." Environment and Planning, 35: 1331-1338. 